\title{
Analgesic efficacy of sodium salicylate in an amphotericin B-induced bovine synovitis-arthritis model
}

\author{
J. L. Kotschwar, ${ }^{*}$ J. F. Coetzee, ${ }^{* 1}$ D. E. Anderson, ${ }^{*}$ R. Gehring, ${ }^{*}$ B. KuKanich, $†$ and M. D. Apley \\ ${ }^{*}$ Department of Clinical Sciences, and \\ †Department of Anatomy and Physiology, College of Veterinary Medicine, Kansas State University, Manhattan 66506-5601
}

\begin{abstract}
This study examined the efficacy of sodium salicylate for providing analgesia in an amphotericin B-induced bovine synovitis-arthritis model using 10 male Holstein calves, 4 to 6 mo old and weighing approximately $250 \mathrm{~kg}$. The study used a repeated measures partial crossover design with 2 phases, consisting of 3 treatment periods within each phase. Calves were blocked by body weight and randomly assigned to the sodium salicylate $(50 \mathrm{mg} / \mathrm{kg}$ i.v.) or placebo group for phase 1 . In period 1, lameness induction was simulated with a needle prick of the coronary band, followed by drug or placebo administration. At predetermined time points, serial blood samples for cortisol and salicylate concentrations, electrodermal activity measurements, heart rates, and pressure mat data were collected. Visual lameness scores were recorded by an observer blinded to treatments. In period 2, lameness was induced with injection of amphotericin B into the distal interphalangeal joint, followed by drug or placebo administration, with sample collection as described previously. In period 3, the drug or placebo was administered to the respective calves with sample collection. After a 10-d washout period, phase 2 was conducted with treatments crossed over between groups. Cortisol and salicylate samples were analyzed by competitive chemiluminescent immunoassay and fluorescence polarization immunoassay, respectively. The pharmacokinetic data were analyzed using compartmental analysis. Mean intravenous salicylate apparent volume of distribution was $0.2 \pm 0.005 \mathrm{~L} / \mathrm{kg}$, total body clearance was $4.3 \pm$ $0.2 \mathrm{~mL} / \mathrm{min} \cdot \mathrm{kg}$, and elimination half-life was $36.9 \pm 1.2$ min. The repeated measures data were analyzed based on a univariate split-plot approach with a random effects-mixed model. Differences in stance phase duration and serum cortisol concentration values were seen both between periods and between treatment group $\times$ periods; differences in heart rate, contact surface area,
\end{abstract}

Received January 21, 2009

Accepted April 29, 2009.

${ }^{1}$ Corresponding author: jcoetzee@vet.ksu.edu and contact pressure values were seen between periods, suggesting that our lameness model was effective. No differences were seen between treatment groups. When analyzed by visual lameness score, differences were seen in heart rate, contact surface area, contact pressure, and cortisol concentrations. Area under the time-effect curves, determined by using the trapezoidal rule, had results similar to the repeated measures data, except for a difference in period for electrodermal activity. This amphotericin B-induced synovitis-arthritis model is a useful tool for studying changes associated with lameness in cattle. Sodium salicylate was not effective in providing analgesia after lameness.

Key words: salicylate, amphotericin B, lameness, pain

\section{INTRODUCTION}

Over the past decade, the issue of food animal welfare has come to the forefront of veterinary medicine (American Veterinary Medical Association, 2001). Much of this interest has centered on pain management, in relation to both routine production practices and pain involving diseases encountered in production environments.

Lameness is one of the most common reasons for premature culling in dairy cows and is also an important cause of loss in beef cattle (Berry, 2001). Cook (2003) found the prevalence of lameness in dairy cows to be as high as 33.7\%. The 1999 National Market Cow and Bull Beef Quality Audit was conducted to examine the quality of market cows and bulls and for comparison with data collected from the 1994 National Non-Fed Beef Quality Audit. Roeber et al. (2001) found that $31.4 \%$ of all cattle audited were lame and that losses attributable to lameness were significantly greater than reported in the 1994 audit. Of all cattle, $7.4 \%$ of carcasses had one arthritic joint that required removal at slaughter, and $4.0 \%$ of carcasses had 2 arthritic joints that were removed.

To evaluate pain and then evaluate interventions, an objective method of measurement is required. Pain assessment is difficult in stoic species such as cattle. 
Most research has focused on behavioral or physiological changes associated with acute pain (Anil et al., 2002; Ting et al., 2003; Stilwell et al., 2008), but these changes can be complex, with natural variation between animals complicating the differentiation of pain from other factors such as stress (Anderson and Muir, 2005).

In addition to variations in physiological responses, variations in disease severity also complicate the study of pain. Induction of lameness allows for controlled evaluation of pain in animals because pre- and postlameness measurements can be taken from the same animal, thereby reducing the confounding effects of individual differences. Well-controlled bovine lameness induction models are scarce in the published literature. Models based on intraarticular inoculation of bacteria are difficult to standardize and control, and often cause intense and prolonged pain (Francoz et al., 2008). Amphotericin B, a polyene antibiotic, produces a controlled, mild to moderately severe synovitis-arthritis of short duration (Fahmy et al., 1994). Thus, an amphotericin B-induced arthritis model is ideal for evaluating analgesic compounds such as sodium salicylate.

Currently, no drugs are approved by the US Food and Drug Administration specifically to provide analgesia in cattle (Smith et al., 2008). This absence of approved compounds leaves veterinarians to make extrapolations about the proper clinical use of drugs applied for these purposes from data developed in other species. Presently, flunixin meglumine is the only approved nonsteroidal antiinflammatory drug labeled for use in cattle, and its use is limited to the treatment of fever and inflammation. This drug is undesirable in many lameness cases because prolonged use is associated with abomasal ulcers and nephrotoxicity (Anderson and Muir, 2005). Therefore, it is important to identify other analgesic compounds with fewer undesirable side effects for providing relief of chronic pain in cattle. Sodium salicylate is a commonly used antiinflammatory drug in multiple species (USP Veterinary Pharmaceutical Information Monographs, 2004), but the efficacy of sodium salicylate for analgesia related to arthritis in cattle has not been determined. The FDA Center for Veterinary Medicine guidance for the development of effectiveness data for nonsteroidal antiinflammatory drugs indicates that validated methods of pain assessment must be used for a drug to be indicated for pain relief in the target species.

Several tools have been described to assess pain associated with lameness in cattle. No single lameness grading system has been universally accepted for lameness scoring in cattle. One of the most common lameness scoring systems is based on visual gait analysis, based on behavior and posture (Sprecher et al., 1997). This system is most useful in categorizing general lameness for serial monitoring, in setting intervention points for herd level decisions, and in identifying individuals for immediate treatment. Although visual scoring systems do allow for noninvasive categorization of lameness that can be correlated with the other diagnostic tools, they are limited by inter- and intraobserver variability. Wells et al. (1993) found 91.3\% interobserver agreement between 2 investigators when using a standardized visual lameness scoring system. However, objective assessment tools in support of drug approvals are needed and must be validated for use in cattle.

Multiple assessment tools for pain or loss of function have been proposed. Pressure mat technology provides objective data through determination of BW distribution and temporality. This allows for noninvasive analysis of lameness that can be correlated with the other diagnostic tools. Electrodermal activity (EDA) is a noninvasive technique that is advocated as an objective measurement of pain. The proposed mechanism is that afferent neurons from the sympathetic axis of the autonomic nervous system innervate eccrine sweat glands, resulting in modulations of skin electrical conductance known as EDA (Anderson and Muir, 2005). The determination of serum cortisol concentration is a physiological measurement to allow for minimally invasive measurement of stress in animals (Coetzee et al., 2007). Heart rate monitors use a noninvasive method to evaluate changes in symphathovagal tone related to stress attributable to emotional, pathological, or physiological causes (von Borell et al., 2007).

We hypothesized that intraarticular amphotericin B produces a controlled, transient synovitis-arthritis in cattle and that this model could describe the analgesic effects of intravenous sodium salicylate. Amphotericin B-induced lameness in cattle was quantified by using subjective visual gait assessments and objective pressure mat, EDA, cortisol, and heart rate measurements.

\section{MATERIALS AND METHODS}

All experimental procedures in this study were approved by the Kansas State University Institutional Animal Care and Use Committee under the supervision of the University Veterinarian.

\section{Experimental Cattle}

Ten Holstein bull calves aged 2 to 4 mo were acquired from a Kansas livestock producer in June 2008. Weights obtained approximately $20 \mathrm{~d}$ before commencing the study in September ranged from 231 to $286 \mathrm{~kg}$. 


\section{Phase 1 Period 1 (baseline data)}

\begin{tabular}{|c|c|c|}
\hline $\begin{array}{l}\text { All calves receive needle prick to right } \\
\text { lateral hindlimb coronary band }\end{array}$ & $\begin{array}{c}\text { Treated calves receive } 50 \mathrm{mg} / \mathrm{kg} \\
\text { intravenous sodium salicylate, control } \\
\text { calves receive sterile water }\end{array}$ & Data collected on all calves \\
\hline \multicolumn{3}{|c|}{ Phase 1 Period 2 (analgesia at lameness induction) } \\
\hline $\begin{array}{l}\text { All calves receive } 20 \mathrm{mg} \text { intra-articular } \\
\text { Amphotericin B in right lateral distal } \\
\text { interphalangeal joint }\end{array}$ & $\begin{array}{c}\text { Treated calves receive } 50 \mathrm{mg} / \mathrm{kg} \\
\text { intravenous sodium salicylate, control } \\
\text { calves receive sterile water }\end{array}$ & Data collected on all calves \\
\hline \multicolumn{3}{|c|}{ Phase 1 Period 3 (analgesia 24 hours post-lameness induction) } \\
\hline $\begin{array}{l}\text { Treated calves receive } 50 \mathrm{mg} / \mathrm{kg} \text { intraveno } \\
\text { control calves receive sterile }\end{array}$ & $\begin{array}{l}\text { odium salicylate, } \\
\text { ater }\end{array}$ & cted on all calves \\
\hline \multicolumn{3}{|c|}{10 day washout, treatment groups switched } \\
\hline \multicolumn{3}{|c|}{ Phase 2 Period 1 (baseline data) } \\
\hline $\begin{array}{l}\text { All calves receive needle prick to left lateral } \\
\text { hindlimb coronary band }\end{array}$ & $\begin{array}{c}\text { Treated calves receive } 50 \mathrm{mg} / \mathrm{kg} \\
\text { intravenous sodium salicylate, control } \\
\text { calves receive sterile water }\end{array}$ & Data collected on all calves \\
\hline
\end{tabular}

\begin{tabular}{|c|c|c|}
\hline \multicolumn{2}{|c|}{ Phase 2 Period 2 (analgesia at lameness induction) } \\
\hline $\begin{array}{c}\text { All calves receive } 15 \mathrm{mg} \text { intra-articular } \\
\text { Amphotericin B in left lateral distal } \\
\text { interphalangeal joint }\end{array}$ & $\begin{array}{c}\text { Treated calves receive } 50 \mathrm{mg} / \mathrm{kg} \\
\text { intravenous sodium salicylate, control } \\
\text { calves receive sterile water }\end{array}$ & Data collected on all calves \\
\hline \multicolumn{2}{|c|}{ Phase 2 Period 3 (analgesia 24 hours post-lameness induction) } \\
\hline $\begin{array}{c}\text { Treated calves receive } 50 \text { mg/kg intravenous sodium salicylate, } \\
\text { control calves receive sterile water }\end{array}$ & Data collected on all calves \\
\hline
\end{tabular}

Figure 1. Flowchart of the crossover study design. 
On arrival, the calves received a single subcutaneous dose of a 8-way clostridial vaccine (Covexin 8 , Schering Plough, Summit, NJ), a single intramuscular dose of a 4-way modified live viral respiratory disease vaccine (Bovi-shield Gold 4, Pfizer, New York, NY), a single subcutaneous injection of tulathromycin at $2.5 \mathrm{mg} / \mathrm{kg}$ of BW (Draxxin, Pfizer). A topical pour-on (Ultra Boss Pour-on, Schering-Plough Animal Health) was applied on arrival and repeated approximately every 7 to $10 \mathrm{~d}$ for fly control. Approximately 2 wk after arrival, the calves were dehorned and castrated. Approximately 1 mo after initial processing, the cattle were given a single-dose subcutaneous implant at the base of the ear, containing trenbolone acetate and estradiol benzoate, for steers intended for slaughter (Synovex Choice, Fort Dodge Animal Health, Fort Dodge, IA), a single dose of topical doramectin at $500 \mu \mathrm{g} / \mathrm{kg}$ of BW (Dectomax Pour-on, Pfizer), and a single subcutaneous injection at the base of the ear of ceftiofur crystalline-free acid at $6.6 \mathrm{mg}$ of ceftiofur $\mathrm{Eq} / \mathrm{kg}$ of BW (Excede, Pfizer Animal Health).

\section{Housing and Husbandry}

Study calves were initially housed in a dry lot confinement facility at the Kansas State University Animal Resource Facility for approximately $90 \mathrm{~d}$ after arrival. Thereafter, calves were acclimated to individual 13.40 $\mathrm{m}^{2}$ indoor stalls in an Animal Resource Facility barn for $2 \mathrm{~d}$ before the study commenced. Each stall was separated by a gate. During the adaptation period, each animal was restrained for at least 10 to $15 \mathrm{~min} / \mathrm{d}$, using a squeeze chute with head gate, was tied with a rope halter to the fence within the pen for at least 10 $\mathrm{min} / \mathrm{d}$, and was trained to walk through an alleyway to allow for restricted access across a pressure mat at least twice daily. For the entire housing period, calves had free access to water and brome hay along with a daily feeding of $3.6 \mathrm{~kg} /$ animal of a balanced beef feedlot receiving diet composed of cracked corn, whole oats, whole milo, dry distillers grains, and a protein-vitaminmineral supplement.

\section{Jugular Catheterization}

Approximately $24 \mathrm{~h}$ before the study commenced, all calves were individually restrained in a squeeze chute by using a rope halter and the attached head gate. After restraint, the area over the right jugular vein in phase 1 and over the left jugular vein in phase 2 was clipped and disinfected using povidone iodine and 70\% isopropyl alcohol swabs. The catheter site was infiltrated with approximately $0.5 \mathrm{~mL}$ of $2 \%$ lidocaine injection (Hospira Inc., Lake Forest, IL) and a small skin incision with a number 22 blade was made to facilitate placement of a 14-gauge $\times 140$-mm catheter (Abbocath-T, Abbott Ireland, Sligo, Ireland), which was sutured to the skin using 2-0 nylon suture (Burns Veterinary Supply Inc., Westbury, NY). Catheter patency was maintained using $3 \mathrm{~mL}$ of heparin saline flush containing 3 USP units of heparin sodium $/ \mathrm{mL}$ of $0.9 \%$ saline (Heparin Sodium Injection, USP, Baxter Healthcare, Deerfield, IL). The catheters were removed immediately after the last blood collection time point in each phase.

\section{Group Assignment, Randomization, and Study Procedures}

The study design was a partial crossover design with 2 phases. Each phase consisted of 3 periods (Figure 1). Study animals were blocked in pairs according to their BW, as determined approximately $20 \mathrm{~d}$ before the study commenced. The heaviest 8 of 10 calves were selected for inclusion in phase 1 of the study, with the remaining 2 serving as replacements if needed. Calves were ranked by ascending $\mathrm{BW}$ in kilograms and assigned a computer-generated random number (Excel 2007, Microsoft Corporation, Redmond, WA). Pairs were then assigned based on relative similar BW. In each pair, calves with the highest random number were assigned to the salicylate group for phase 1 , whereas the remaining calves were designated as placebo control calves (n $=4$ calves (group). These treatment assignments were then reversed for phase 2. After randomization, the mean prestudy BW of calves enrolled in the phase 1 treatment and control groups were $262 \pm 9.8$ and $263 \pm$ $18.1 \mathrm{~kg}$, respectively. The mean prestudy BW of calves included in the phase 2 treatment and control groups were $260 \pm 22.8$ and $257 \pm 22.2 \mathrm{~kg}$, respectively.

The study commenced at $0645 \mathrm{~h}$ with a mock lameness induction (period 1) and the lameness induction (period 2) occurring with 4-min intervals between calves. The mock lameness induction was performed by applying a needle prick to the coronary band at the site of the amphotericin B injection. The purpose of period 1 was to collect nonarthritis baseline data after the needle prick alone to compare with the data collected after induction of distal interphalangeal joint arthritis during lameness. The mock lameness induction and lameness induction were completed by $0715 \mathrm{~h}$; all procedures were performed by a single veterinarian (D. E. A.) to avoid interoperator variation. Period 3 began $24 \mathrm{~h}$ after the induction of lameness for evaluation of postemptive analgesia. During this period, there were no further lameness-inducing procedures; the only manipulations were the administration of drug (or placebo) and the collection of data. 


\section{Lameness Induction}

Before the sham lameness induction and lameness induction, all calves were restrained in a chute with head gate as conducted through the acclimatization period, and the appropriate hind leg (phase 1: right leg; phase2: left leg) was restrained with ropes at the fetlock and stifle. After restraint, the appropriate hindlimb lateral digit pastern region was prepared with close clipping of hair (no. 40 clipper blade) and aseptic skin preparation by using a povidone iodine scrub and $70 \%$ isopropyl alcohol swabs. Mock induction of lameness occurred in period 1 by introducing a sterile 18-gauge 1.5-in. needle $1 \mathrm{~cm}$ proximal to the coronary band and $1 \mathrm{~cm}$ abaxial to the tendon of the long digital extensor muscle and angling distally toward the sole. No solutions were injected into the joint, and the needle was removed immediately. One day of washout was allowed between periods 1 and 2 . In period 2, the above procedure was repeated, with the exception of injecting amphotericin B (X-Gen Pharmaceuticals Inc., Big Flats, NY). After the sterile needle was inserted, correct placement into the distal interphalangeal joint was verified by aspiration of synovial fluid back into the syringe. Continued positioning within the distal interphalangeal joint was verified periodically throughout the injection by ease of injection, followed by back-flow of synovial fluid and amphotericin B into the syringe. This admixture was then fully injected into the distal interphalangeal joint to complete the procedure. In phase 1 , the dose was $20 \mathrm{mg}$, using $2 \mathrm{~mL}$ of a $10 \mathrm{mg} / \mathrm{mL}$ solution. In phase 2 , the dose was decreased to $15 \mathrm{mg}$, using $3 \mathrm{~mL}$ of a 5 $\mathrm{mg} / \mathrm{mL}$ solution. Concentration of amphotericin B and total dose of the drug was reduced in phase 2 in an attempt to lessen the duration of lameness experienced by the calves.

Escape analgesic therapy options for unresolved lameness after the final data collection for each phase included flunixin meglumine at $2.2 \mathrm{mg} / \mathrm{kg}$ i.v. once daily, butorphanol tartrate at $0.05 \mathrm{mg} / \mathrm{kg}$ s.c. once daily, morphine at $0.1 \mathrm{mg} / \mathrm{kg}$ s.c. once daily, and lidocaine $2 \%$, with a total dose of $100 \mathrm{mg}$ intraarticularly once.

\section{Drug Administration}

Within each phase of the study, placebo controlarthritis group calves received $50 \mathrm{~mL}$ of sterile water i.v. (Baxter Healthcare) 4 min after lameness induction through a preplaced jugular catheter in each period, whereas the salicylate-treated calves received $50 \mathrm{mg} /$ $\mathrm{kg}$ of commercially available laboratory grade sodium salicylate (Sigma-Aldrich, St. Louis, MO) dissolved in sterile water (Baxter Healthcare) for a total volume of $50 \mathrm{~mL}$ i.v. through the jugular catheter 4 min after lameness induction in each period. Doses were based on BW obtained $24 \mathrm{~h}$ before administration. Immediately after placebo or drug administration, the catheter was flushed by using $3 \mathrm{~mL}$ of heparin saline flush solution as described above.

\section{Blood Sample Collection}

Twenty milliliters of whole blood for salicylate concentration in treated calves and cortisol concentration in all calves was collected into syringes using the preplaced jugular catheter immediately before drug or placebo administration, and again at 5, 10, 20, 30, and $45 \mathrm{~min}$, and $1,1.5,2,3,4,5,6,8,10$, and $12 \mathrm{~h}$ thereafter. Immediately after obtaining the blood sample, $3 \mathrm{~mL}$ of heparin saline flush, as described above, was used to maintain patency of the catheter. Blood was immediately transferred to a $7-\mathrm{mL} \mathrm{K}_{2}$-EDTA tube (BD Diagnostics, Franklin Lakes, NJ) containing $350 \mu \mathrm{L}$ of aprotinin $(1,000 \mathrm{kIU} / \mathrm{mL})$, a serine protease inhibitor (Santa Cruz Biotechnology Inc., Santa Cruz, CA), and a 7-mL Vacutainer tube (BD Diagnostics) containing no additive. The Vacutainer tubes were stored on ice for no more than 60 min pending sample processing. Thereafter, blood samples were centrifuged at 1,600 g for $15 \mathrm{~min}$ at $0^{\circ} \mathrm{C}$. Serum and plasma were pipetted from their respective tubes and placed in cryovials identified with calf identification number, date, time point sample, and treatment group. The samples were stored at $-40^{\circ} \mathrm{C}$ before sample analysis. All samples were analyzed within $60 \mathrm{~d}$ of sample collection.

\section{Cortisol Analysis}

Serum cortisol concentrations were determined as described previously and validated in bovine plasma (Coetzee et al., 2007) by using a solid-phase competitive chemiluminescent enzyme immunoassay and an automated analyzer system (Immulite 1000 Cortisol, Siemens Medical Solutions Diagnostics, Los Angeles, CA). A sample volume of $100 \mu \mathrm{L}$ was used in each assay well. The reported calibration range for the assay is 28 to $1,380 \mathrm{nmol} / \mathrm{L}$, with an analytical sensitivity of $5.5 \mathrm{nmol} / \mathrm{L}$.

\section{Salicylate Analysis}

Plasma salicylate concentrations were determined by using a fluorescence polarization immunoassay kit (TDx/TDxFLx, Abbott Laboratories, Abbott Park, IL) validated in our laboratory (Coetzee et al., 2007). The concentration of salicylate in unknown samples was calculated from a calibration curve by using a best fit-curve equation determined by using 6 calibrations 
points with a detection concentration range between 5 and $800 \mu \mathrm{g} / \mathrm{mL}$. The limit of quantitation (LOQ) of the assay was $5 \mu \mathrm{g} / \mathrm{mL}$. The precision of the assay was less than an $8 \%$ coefficient of variation. The accuracy by recovery at concentrations of $50,100,200,400$, and $800 \mu \mathrm{g} / \mathrm{mL}$ was between 98.3 and $102.5 \%$.

\section{Pharmacokinetic Analysis}

Compartmental pharmacokinetic analysis of the salicylate time concentration data was performed using a commercially available software program (WinNonlin, Pharsight Corporation, Cary, NC). A one-compartment model with first-order elimination was found to fit the data best, based on visual inspection of predicted versus observed data plots and 2 measures of goodness of fit (Akaike's information criterion and Schwarz's Bayesian criterion). The data were therefore fit to exponential equation [1] by nonlinear regression analysis,

$$
\mathrm{C}(\mathrm{t})=\frac{\text { Dose }}{\mathrm{V}_{\text {area }}} \times \mathrm{e}^{-K_{10} \times \text { time }},
$$

where $V_{\text {area }}$ is the apparent volume of distribution and $K_{10}$ is the elimination rate constant, determined by the slope of the terminal elimination phase with the timeconcentration data plotted on a semilogarithmic scale.

The following secondary parameters were also calculated: area under the time-concentration curve (AUC), elimination half-life $\left(\mathrm{T}_{1 / 2} \mathrm{el}\right)$, concentration at time zero $\left(\mathrm{C}_{0}\right)$ and total body clearance $\left(\mathrm{CL}_{\mathrm{B}}\right)$, mean residence time (MRT), and volume of distribution $\left(\mathrm{V}_{\mathrm{d}}\right)$ at steady state $\left(\mathrm{V}_{\mathrm{ss}}\right.$; equations [2] to [7]); $\mathrm{AUMC}=$ area under the moment curve:

$$
\begin{gathered}
\mathrm{AUC}=\frac{\text { Dose }}{\mathrm{V}_{\mathrm{d}(\text { area }) \times K_{10}}}, \\
\mathrm{~T}_{1 / 2} \mathrm{el}=\frac{0.693}{K_{10}}, \\
\mathrm{C}_{0}=\frac{\text { Dose }}{\mathrm{V}_{\mathrm{d}}}, \\
\mathrm{CL}_{\mathrm{B}}=K_{10} \times \mathrm{V}_{\mathrm{d}}, \\
\mathrm{MRT}=\frac{\mathrm{AUMC}}{\mathrm{AUC}}, \\
\mathrm{V}_{\mathrm{ss}}=\frac{\text { Dose } \times \mathrm{AUMC}^{2} .}{\mathrm{AUC}^{2}} .
\end{gathered}
$$

\section{Pressure Mat Analysis}

A commercially available floor mat-based pressure/ force measurement system (MatScan, Tekscan Inc., South Boston, MA) was used to record and analyze the affected feet of each calf. The pressure mat was calibrated daily, and each time, the computer software was engaged using a known mass to ensure accuracy of the measurements at each time point. Video synchronization was used to ensure a consistent gait between and within calves for each time point. Using research-grade software (Hugemat Research 5.83, Tekscan Inc.), contact pressure, contact area, and stance phase duration in the affected feet were measured. Surface area was calculated by area only of the loaded or "contact"sensing elements inside the measurement box. Contact pressure was calculated as force on the loaded sensing elements inside the measurement box divided by the contact area.

\section{Heart Rate}

Heart rate data were recorded and analyzed using a commercially available heart rate monitor and software (RS800 and Polar Pro Trainer Equine Edition, Polar Electro Inc., Lake Success, NY). The heart rate product consisted of a transmitter placed over the heart in the left foreflank attached to a girth strap placed around the heart girth of the calves, and a wrist unit attached to the elastic strap, which received and recorded the signal from the transmitter. Appropriate conductance for the electrodes on the strap, one positioned on the sternum and one over the right scapula, was facilitated by using ultrasound gel. The transmitter measured the electric signal (electrocardiogram) of the heart every $15 \mathrm{~s}$. Before the study commenced, the heart rate wrist unit time was synchronized with the stopwatches used for all other sample collection. The corresponding heart rate within $15 \mathrm{~s}$ of each time point was used for analysis.

\section{EDA}

A commercially available EDA-galvanic skin response measurement device (Pain Gauge, PHIS Inc., Dublin, $\mathrm{OH})$ was used to measure the EDA on the nasal planum of each of the calves. It converted the level of resistance measured between 2 electrodes to a 10-point scale with detection at the 0.1 level, with 0 representing "calm/no pain" and 9.9 representing "tense/severe pain."

\section{Clinical Evaluation}

The degree of lameness was scored using a 1 to 5 scale adapted from Sprecher et al. (1997; Table 1). Lame- 
Table 1. Sprecher lameness scoring system

\begin{tabular}{ll}
$\begin{array}{l}\text { Lameness } \\
\text { score }\end{array}$ & Clinical description \\
\hline 1 & Normal-Stands and walks normally, with all feet placed with purpose \\
2 & Mildly lame-Stands with flat back, but arches when walks; gait is slightly abnormal \\
3 & Moderately lame-Stands and walks with an arched back and short strides with one or more legs \\
4 & Lame-Arched back standing and walking, with one or more limbs favored but at least partially weight bearing \\
5 & Severely lame-Arched back; refuses to bear weight on one limb; may refuse or have great difficulty moving from a lying position \\
\hline
\end{tabular}

ness scores were determined twice daily to document the presence of lameness and to score the severity of lameness visually. To eliminate interobserver variation, all lameness scores were assigned by one veterinarian blinded to treatment (D. E. A.) with training and expertise in bovine lameness assessment. Intraobserver variability was assessed periodically by randomly selecting calves for repeated assessment to ensure consistency of scoring. All lameness examinations were performed on even, nonsloped concrete floors free of obstructions and debris. Each lameness score was determined by watching the calf walk a minimum of $20 \mathrm{~m}$ in a straight line, turn, and walk $20 \mathrm{~m}$ back to the starting point.

\section{Data Analysis and Statistics}

Hypothesis tests were conducted using JMP 5.1.2 analytical software (SAS Institute Inc., Cary, NC; Sall et al., 2004). The means \pm standard errors of the means were calculated for each outcome variable at each time point. Repeated measures data were analyzed using a univariate split-plot approach. A random effects-mixed model was constructed, with treatment, time, the time $\times$ treatment interaction, period, and the period $\times$ treatment interaction designated as fixed effects. In this model, animal nested in treatment was designated as a random effect to account for the between-subjects effects. Statistical significance was designated a priori as $P<0.05$. Areas under the time-effect curves (AUEC) were determined as described previously (Leon-Reyes et al., 2008) with the commercially available software program WinNonlin (Pharsight Corporation, Cary, NC) using the linear trapezoidal rule. Analysis of variance, by Tukey's test, was used to evaluate differences, with statistical significance considered at $P<0.05$.

\section{RESULTS}

The AUEC and repeated measures analysis for cortisol response, heart rate, electrodermal activity, and the surface area, contact pressure, and stance phase duration recorded on the pressure mat are presented in Table 2. Period 1 represents baseline concentrations with period 2 representing the period immediately fol- lowing lameness induction, and period 3 representing the period $24 \mathrm{~h}$ post-lameness induction. The effect of period $\times$ treatment group on the parameters is reported in Table 2 for the repeated measures analysis and AUEC analysis.

\section{Cortisol Concentration}

Cortisol mean concentrations were greater in period 2 than in period 1 or 3 , both as evaluated by overall period mean $(P<0.0001$, AUEC $P<0.0001)$ and as evaluated for each treatment between periods (treatment group $\times$ period interaction, $P=0.017$ ), indicating an acute response to the arthritis induction. No difference was found between treatment $(P=0.695$, AUEC $P=0.912)$. Differences were seen in time $(P<$ $0.0001)$ and the interaction time $\times$ treatment group $(P$ $=0.018)$.

\section{Salicylate Concentration}

After intravenous administration, sodium salicylate was not widely distributed and plasma concentrations declined rapidly below the LOQ of the assay $(5 \mu \mathrm{g} /$ $\mathrm{mL})$ by $240 \mathrm{~min}(4 \mathrm{~h})$ after administration. Because a 1-compartment model was used, all estimates of the apparent volume of distribution $\left[\mathrm{V}_{\mathrm{d}(\text { area })}\right.$ and $\left.\mathrm{V}_{\mathrm{d}(\mathrm{ss})}\right]$ were equal. The mean $\mathrm{V}_{\mathrm{d}}$ was $0.2 \pm 0.005 \mathrm{~L} / \mathrm{kg}, \mathrm{CL}_{\mathrm{B}}$ was 4.3 $\pm 0.2 \mathrm{~mL} / \mathrm{min} \cdot \mathrm{kg}$, and $\mathrm{T}_{1 / 2} \mathrm{el}$ was $36.9 \pm 1.2 \mathrm{~min}$. The average plasma time-concentration curve is illustrated in Figure 2. The other pharmacokinetic parameters for intravenous sodium salicylate are reported in Table 3.

\section{Pressure Mat Analysis}

Contact Surface Area. Contact surface area of the affected foot was greater in period 1 compared with those in periods 2 and $3(P<0.0001)$, and was greater in period 1 compared with that in period 2 in AUEC $(P=0.045)$. There was also a difference by time $(P=$ $0.0008)$, in which the surface area at $8 \mathrm{~h}$ after lameness induction was less than at 0 min and $1.5 \mathrm{~h}$. No difference was seen in treatment group $(P=0.430$, AUEC $P=0.369)$, time $\times$ treatment group $(P=0.280)$, or treatment group $\times$ period $(P=0.228)$. 
Table 2. Effect of period on cortisol, surface area, contact pressure, stance phase duration, heart rate, and electrodermal activity data comparing repeat measures analysis to area under the time-effect curves (AUEC)

\begin{tabular}{|c|c|c|c|c|c|c|c|}
\hline \multirow[b]{2}{*}{ Parameter } & \multirow[b]{2}{*}{ Method of analysis } & \multicolumn{2}{|c|}{ Period 1} & \multicolumn{2}{|c|}{ Period 2} & \multicolumn{2}{|c|}{ Period 3} \\
\hline & & $\begin{array}{l}\text { Control LSM } \\
\quad \pm \text { SEM }\end{array}$ & $\begin{array}{l}\text { Salicylate LSM } \\
\quad \pm \text { SEM }\end{array}$ & $\begin{array}{l}\text { Control LSM } \\
\quad \pm \text { SEM }\end{array}$ & $\begin{array}{l}\text { Salicylate LSM } \\
\quad \pm \text { SEM }\end{array}$ & $\begin{array}{l}\text { Control LSM } \\
\quad \pm \text { SEM }\end{array}$ & $\begin{array}{l}\text { Salicylate LSM } \\
\quad \pm \text { SEM }\end{array}$ \\
\hline \multirow[t]{2}{*}{ Cortisol (nmol/L) } & Repeated measures & $46.41 \pm 3.38^{\mathrm{a}}$ & $40.81 \pm 2.94^{\mathrm{a}}$ & $62.00 \pm 3.11^{\mathrm{b}}$ & $73.60 \pm 2.91^{\mathrm{b}}$ & $36.51 \pm 3.33^{\mathrm{a}}$ & $43.71 \pm 3.03^{\mathrm{a}}$ \\
\hline & AUEC & $439.99 \pm 101.04$ & $314.41 \pm 93.55$ & $767.65 \pm 101.04$ & $839.42 \pm 93.55$ & $322.83 \pm 101.04$ & $335.52 \pm 93.55$ \\
\hline \multirow[t]{2}{*}{ Surface area $\left(\mathrm{cm}^{2}\right)$} & Repeated measures & $43.65 \pm 0.77$ & $46.70 \pm 0.70$ & $39.27 \pm 0.76$ & $40.16 \pm 0.70$ & $37.87 \pm 0.76$ & $40.98 \pm 0.70$ \\
\hline & AUEC & $478.52 \pm 31.57$ & $525.60 \pm 29.23$ & $440.42 \pm 31.57$ & $455.89 \pm 29.23$ & $452.23 \pm 31.57$ & $491.43 \pm 29.23$ \\
\hline \multirow[t]{2}{*}{ Contact pressure $\left(\mathrm{kg} / \mathrm{cm}^{2}\right)$} & Repeated measures & $3.52 \pm 0.14$ & $3.60 \pm 0.13$ & $5.13 \pm 0.14$ & $5.14 \pm 0.13$ & $5.24 \pm 0.14$ & $5.03 \pm 0.13$ \\
\hline & AUEC & $41.45 \pm 2.77$ & $42.52 \pm 2.56$ & $61.51 \pm 2.77$ & $60.79 \pm 2.56$ & $62.32 \pm 2.77$ & $58.91 \pm 2.56$ \\
\hline \multirow{2}{*}{ Stance phase duration (s) } & Repeated measures & $0.79 \pm 0.02^{\mathrm{ab}}$ & $0.79 \pm 0.01^{\mathrm{ab}}$ & $0.82 \pm 0.01^{\mathrm{ab}}$ & $0.80 \pm 0.01^{\mathrm{ab}}$ & $0.77 \pm 0.01^{\mathrm{b}}$ & $0.84 \pm 0.01^{\mathrm{a}}$ \\
\hline & AUEC & $8.51 \pm 0.49$ & $8.80 \pm 0.45$ & $9.07 \pm 0.49$ & $8.99 \pm 0.45$ & $9.09 \pm 0.49$ & $9.46 \pm 0.45$ \\
\hline \multirow[t]{2}{*}{ Heart rate (bpm) } & Repeated measures & $82.61 \pm 1.66$ & $84.21 \pm 1.55$ & $86.88 \pm 1.70$ & $89.79 \pm 1.56$ & $97.59 \pm 1.73$ & $104.38 \pm 1.55$ \\
\hline & AUEC & $1,000.97 \pm 77.64$ & $1,069.08 \pm 71.88$ & $1,019.85 \pm 77.64$ & $1,226.86 \pm 71.88$ & $1,204.52 \pm 77.64$ & $1,340.07 \pm 71.88$ \\
\hline \multirow[t]{2}{*}{ Electrodermal activity } & Repeated measures & $8.43 \pm 0.06$ & $8.55 \pm 0.06$ & $8.34 \pm 0.06$ & $8.38 \pm 0.06$ & $8.49 \pm 0.06$ & $8.33 \pm 0.06$ \\
\hline & AUEC & $102.96 \pm 1.15$ & $104.15 \pm 1.06$ & $100.62 \pm 1.15$ & $101.15 \pm 1.06$ & $101.17 \pm 1.15$ & $100.45 \pm 1.06$ \\
\hline
\end{tabular}

${ }^{\mathrm{a}, \mathrm{b}}$ Data points within the same row with differing superscript letters denote statistical significance $(P<0.05)$.
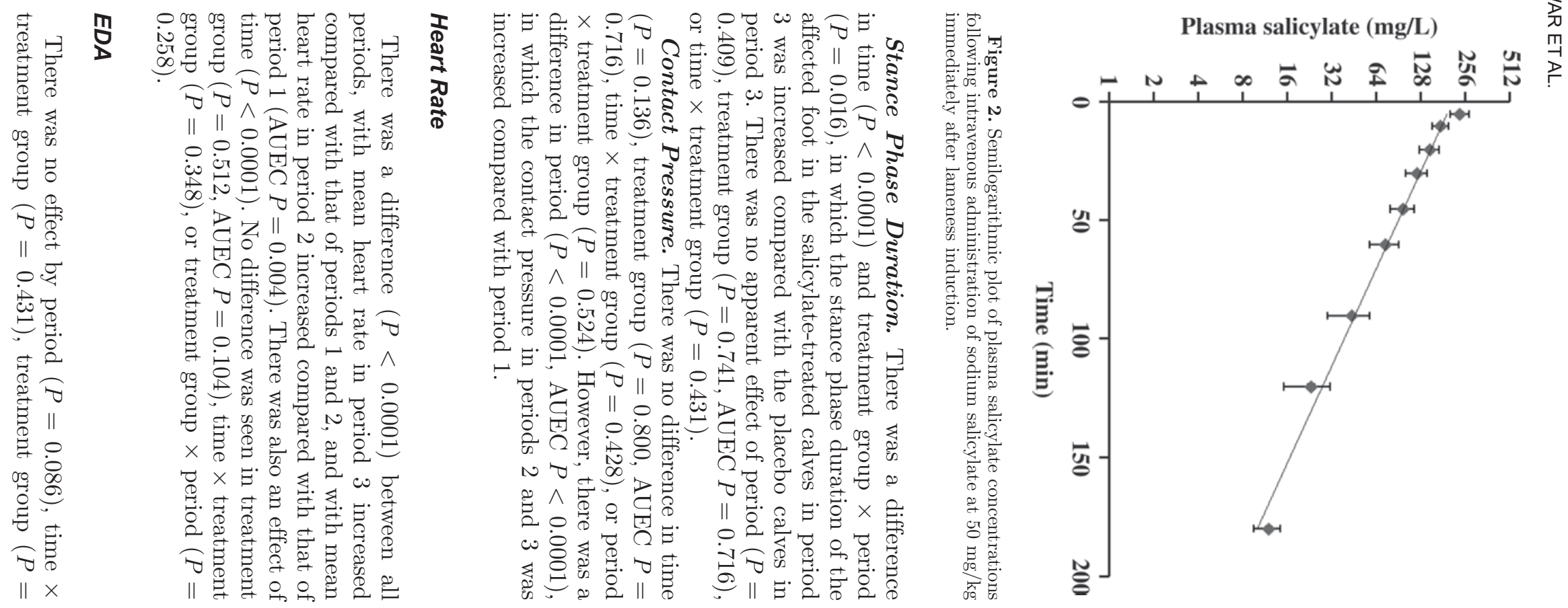
Table 3. Mean \pm standard error of pharmacokinetic parameters describing the disposition of sodium salicylate after administration of $50 \mathrm{mg} / \mathrm{kg}$ i.v. to steers

\begin{tabular}{lc}
\hline Pharmacokinetic parameter $^{1}$ & Mean $\pm \mathrm{SE}$ \\
\hline $\mathrm{AUC}(\mathrm{min} \times \mathrm{mg} / \mathrm{L})$ & $12,099.0 \pm 509.7$ \\
$\mathrm{~T}_{1 / 2} \mathrm{el}(\mathrm{min})$ & $36.9 \pm 1.2$ \\
$K_{10}(1 / \mathrm{min})$ & $0.02 \pm 0.0007$ \\
$\mathrm{C}_{0}(\mathrm{mg} / \mathrm{L})$ & $226.9 \pm 4.9$ \\
$\mathrm{CL}_{\mathrm{B}}(\mathrm{mL} / \mathrm{min} \cdot \mathrm{kg})$ & $4.3 \pm 0.2$ \\
$\mathrm{~V}_{\mathrm{d}}(\mathrm{L} / \mathrm{kg})$ & $0.2 \pm 0.005$ \\
MRT $(\mathrm{min})$ & $53.2 \pm 1.7$ \\
\hline
\end{tabular}

${ }^{1} \mathrm{AUC}=$ area under the curve; $\mathrm{T}_{1 / 2} \mathrm{el}=$ elimination half-life; $K_{10}=$ elimination rate constant; $\mathrm{C}_{0}=$ concentration at time zero; $\mathrm{CL}_{\mathrm{B}}=$ total body clearance; $\mathrm{V}_{\mathrm{d}}=$ volume of distribution; $\mathrm{MRT}=$ mean residence time.

0.976, AUEC $P=0.761)$, or treatment group $\times$ period $(P=0.054)$. There was a difference by period using the AUEC $(P=0.016)$, in which period 1 was increased (an indication of increased pain) compared with periods 2 and 3.

\section{Lameness Score}

When the variables were analyzed by lameness score, some associations were apparent. Mean heart rate was less in lameness score 1 calves compared with heart rates of lameness score 2, 3, and 4 calves (Figure 3). Mean serum cortisol concentrations were less in lameness score 1 calves compared with that of lameness score 3 calves $(P=0.004$; Figure 4$)$. Contact surface area by lameness score was different $(P=0.018)$, with

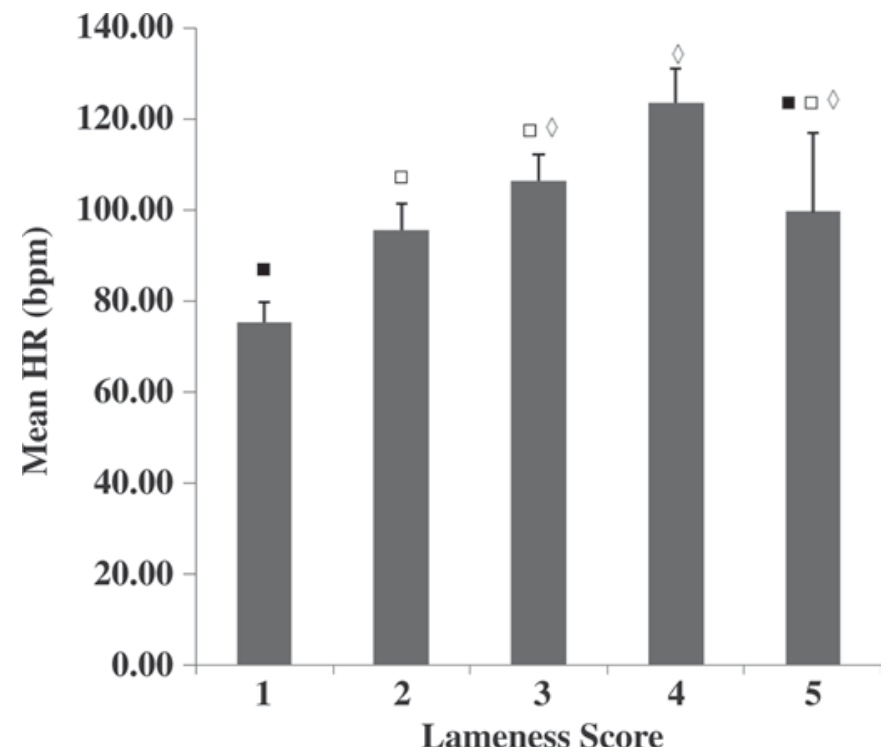

Figure 3. Mean heart rate $(\mathrm{HR}) \pm$ standard error of the mean by lameness score for all treatment groups. Data points with different symbols $(\mathbf{\square}, \square, \diamond)$ indicate $P<0.05$. lameness score 1 calves having a greater surface area compared with lameness score 3 and 4 calves (Figure 5). There was a difference in contact pressure $(P=0.02)$, in which lameness score 3 calves exerted greater ground contact pressure compared with that of lameness score 1 calves (Figure 6). No difference was seen in stance phase duration by lameness score $(P=0.16)$, treatment group $(P=0.68)$, or electrodermal reading $(P=0.29)$. The number of calves within each lameness score for the entire study is contained in Table 4. Three calves (2 salicylate treated and 1 placebo control calf) had unresolved lameness between phases and subsequently were removed from the study.

\section{DISCUSSION}

Improved knowledge of the mechanisms of pain, new veterinary technology, and an increase in concern among consumers about the welfare of livestock has led to a push within the agricultural community to redefine animal welfare (Heleski et al., 2004). Economic loss in all sectors of the cattle industry result from pain and, consequently, decreased feed intake, poor productivity and feed conversion, BW loss, reproductive inefficiency, premature removal from the herd, and death or euthanasia (Hernandez et al., 2002, 2005; Bicalho et al., 2008). The objective of this study was 2 -fold: 1) to determine if the model induced lameness in cattle, and 2 ) to determine if salicylate-treated calves were less affected by the model than control cattle. The results of this study, when comparing differences in variables

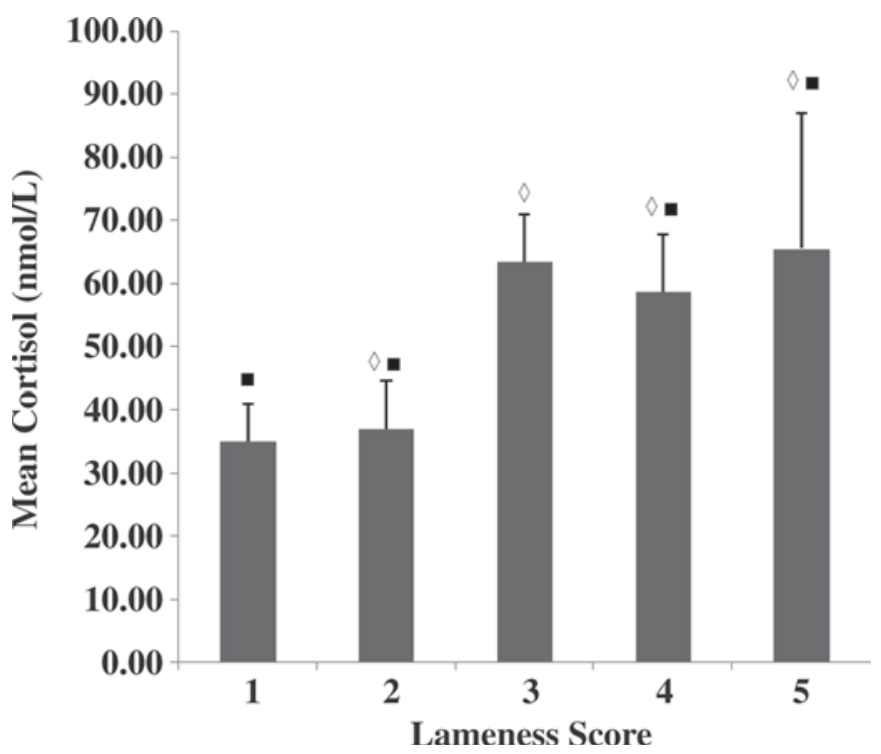

Figure 4. Mean cortisol concentration \pm standard error of the mean by lameness score for all treatment groups. Data points with different symbols $(\mathbf{\square}, \diamond)$ indicate $P<0.05$. 


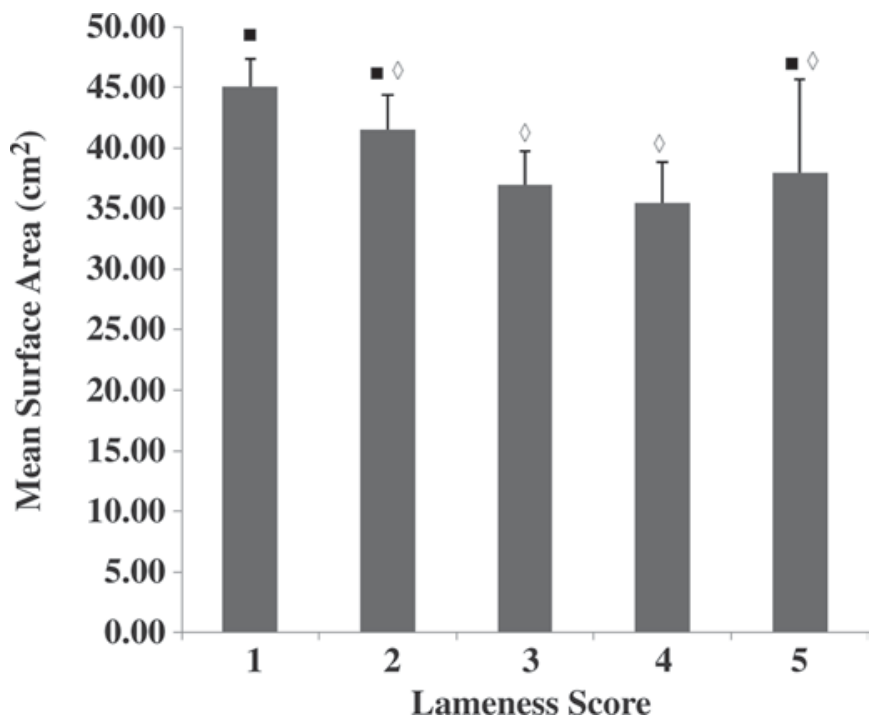

Figure 5. Mean surface area \pm standard error of the mean by lameness score for all treatment groups. Data points with different symbols $(\mathbf{\square}, \diamond)$ indicate $P<0.05$.

before and after lameness, demonstrate that amphotericin B was an effective model to induce lameness. Intravenous sodium salicylate administered once daily at $50 \mathrm{mg} / \mathrm{kg}$ immediately after lameness induction had no effect on cortisol response, EDA, stance phase duration, contact pressure, contact surface area, or heart rate. To our knowledge, this is the first time this amphotericin $\mathrm{B}$ model has been reported in the bovine and the first time pharmacokinetic-pharmacodynamic data for sodium salicylate in an induced lameness model has been studied.

Amphotericin B has been used extensively to induce lameness in horses in studies evaluating lameness, pain, and the effectiveness of certain nonsteroidal antiinflammatory agents and other pain-alleviating agents (Bowman et al., 1983; Crawford et al., 1991; Fahmy et al., 1994; Hegazy et al., 1994; Marttinen et al., 2006). In these studies, a single intraarticular injection of 10 to $20 \mathrm{mg}$ of amphotericin B was effective in inducing lameness. There are no published studies of intraarticular injections of amphotericin B to induce lameness in

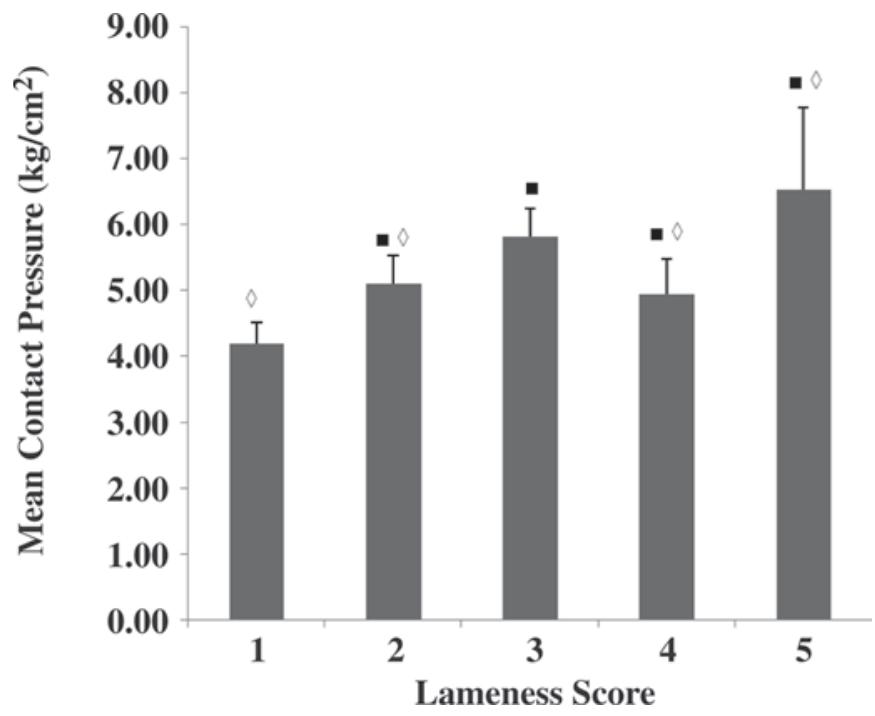

Figure 6. Mean contact pressure \pm standard error of the mean by lameness score for all treatment groups. Data points with different symbols $(\mathbf{\square}, \diamond)$ indicate $P<0.05$.

cattle. Having a model to evaluate parameters before and after lameness induction is very important for evaluating pharmacological agents and establishing dosing regimens. Our results indicate that amphotericin B at 15 and $20 \mathrm{mg}$ administered in a single intraarticular injection is an effective agent to induce lameness in cattle.

The area under the effect curve is an expression of the duration and intensity of an effect. The AUEC has recently been used to describe the pharmacodynamics of the nonsteroidal antiinflammatory drug diclofenac in rats (Leon-Reyes et al., 2008). In that study, researchers found a dose-dependent reduction of analgesic response of orally administered diclofenac by glibenclamide, a sulfonylurea antidiabetic medication. In the present study, the AUEC analysis was similar to the repeated measures analysis. The only difference was in an effect of period on EDA.

Although salicylates are not specifically approved for analgesic use in cattle, the absence of labeled analgesic drugs in this species lends to its use as a pain media-

Table 4. Number of calves within each lameness score by treatment group for the entire study

\begin{tabular}{|c|c|c|c|c|c|c|c|c|c|c|c|c|}
\hline \multirow[b]{3}{*}{ Lameness score } & \multicolumn{4}{|c|}{ Period 1} & \multicolumn{4}{|c|}{ Period 2} & \multicolumn{4}{|c|}{ Period 3} \\
\hline & \multicolumn{2}{|c|}{ Control } & \multicolumn{2}{|c|}{ Salicylate } & \multicolumn{2}{|c|}{ Control } & \multicolumn{2}{|c|}{ Salicylate } & \multicolumn{2}{|c|}{ Control } & \multicolumn{2}{|c|}{ Salicylate } \\
\hline & a.m. & p.m. & a.m. & p.m. & a.m. & p.m. & a.m. & p.m. & a.m. & p.m. & a.m. & p.m. \\
\hline 1 & 6 & 6 & 8 & 8 & 6 & 0 & 8 & 0 & 0 & 0 & 0 & 0 \\
\hline 2 & 1 & 1 & 0 & 0 & 1 & 0 & 0 & 0 & 2 & 5 & 4 & 4 \\
\hline 3 & 0 & 0 & 0 & 0 & 0 & 5 & 0 & 5 & 3 & 1 & 2 & 2 \\
\hline 4 & 0 & 0 & 0 & 0 & 0 & 2 & 0 & 2 & 2 & 1 & 1 & 2 \\
\hline 5 & 0 & 0 & 0 & 0 & 0 & 0 & 0 & 0 & 0 & 0 & 1 & 0 \\
\hline
\end{tabular}


tion drug. Recently, Coetzee et al. (2007) showed that sodium salicylate can be used to moderate pain associated with castration in calves. The castration model may be characterized as acute surgical pain, followed by pain caused by inflammation from the surgical site. The arthritis model reported here is based on induced inflammation, and pharmacokinetic-pharmacodynamic modeling of analgesic drugs is likely different from that associated with the pain of castration. Coetzee et al. (2007) studied the pharmacokinetics of salicylate (50 $\mathrm{mg} / \mathrm{kg}$ i.v.) when it was given, immediately before castration, to Angus crossbred bulls of an age and BW similar to the Holstein calves in our study. The pharmacokinetic results from that study (mean $\mathrm{V}_{\mathrm{d}}$ of 0.18 $\pm 0.01 \mathrm{~L} / \mathrm{kg}, \mathrm{CL}_{\mathrm{B}}$ of $3.36 \pm 0.25 \mathrm{~mL} / \mathrm{min} \cdot \mathrm{kg}, \mathrm{T}_{1 / 2} \mathrm{el}$ of $0.63 \pm 0.04 \mathrm{~h}$ ) were similar to ours. Additionally, their study showed drug concentrations quickly decreasing below the LOQ at $4 \mathrm{~h}$. At this same time point, plasma cortisol concentrations in the salicylate-treated group were similar to those of the castrated control calves. This information, paired with the results of our present study, suggests that the lack of analgesia provided by sodium salicylate in our research most likely was due to the very short half-life of the drug.

The one-compartment model used here for the salicylate pharmacokinetic data produced the best fit despite a biexponential curve that was apparent due to only one sample being taken during the distribution phase. Because the distribution phase was so short, it was considered to be clinically insignificant.

There are no published articles concerning the use of EDA in cattle during lameness. Our research did not find a difference in the treatment groups using EDA. Studies have used EDA as a measurement of pain, anxiety, and stress levels in humans to test new pharmaceutical preparations and to determine the reliability and validity of more subjective tools (Tuschen-Caffier and Vogele, 1999; Schellenberg et al., 2004; Hoferl et al., 2006). One of these studies (Schellenberg et al., 2006) found changes in EDA in individuals suffering from psychoautonomic imbalances under an herbal treatment, but not under benzodiazepine oxazepam. This is an assessment in need of further research.

The cortisol response seen in our research was not affected by administration with sodium salicylate. Serum cortisol measurements have been used extensively in pain research to ascertain the presence of pain (Anil et al., 2002; Ting et al., 2003; Coetzee et al., 2007; Stilwell et al., 2008). Although several studies have evaluated an acute cortisol response as a physiological measure of the extent and duration of stress associated with castration in cattle, it is important to recognize that cortisol is also involved in homeostasis and is therefore not a specific indicator of pain and distress (Anil et al.,
2002). Several published castration studies have evaluated the cortisol response. In a study using $50 \mathrm{mg} / \mathrm{kg}$ i.v. of sodium salicylate immediately before castration (Coetzee et al., 2007), a plasma salicylate concentration above $25 \mu \mathrm{g} / \mathrm{mL}$ was found to attenuate peak cortisol concentrations. Ting et al. (2003) found that ketoprofen in association with castration decreased cortisol concentrations compared with local anesthesia or a caudal epidural. In another castration study by Stilwell et al. (2008), cattle were treated with an epidural injection of lidocaine alone or in addition to a subcutaneous injection of carprofen or flunixin meglumine. They found that control calves had higher concentrations of cortisol at $6 \mathrm{~h}$ after castration compared with calves in the epidural plus carprofen and flunixin groups. Calves in the epidural plus carprofen group had lower cortisol compared with control calves at $24 \mathrm{~h}$ after castration and lower cortisol at $48 \mathrm{~h}$ after castration compared with calves treated with the epidural alone or the epidural plus flunixin.

Unfortunately, there are no studies pertaining to lameness scores and intravenous sodium salicylate in dairy cattle. However, Flower et al. (2008) studied lameness in lactating dairy cows treated with varied doses of ketoprofen, using a lameness score of 1 to 5 that took into consideration the arch of the back, but was not the same lameness scoring system as used in our research. In that study, the authors found that lameness scores improved with the highest dose of ketoprofen, $3.0 \mathrm{mg} /$ $\mathrm{kg}$. This study demonstrates the effectiveness of nonsteroidal antiinflammatory drugs in providing analgesia in lameness. Our research suggested an association between lameness scores and the variables of cortisol concentration, contact surface area, contact pressure, and heart rate. This association warrants further investigation.

Heart rate was not decreased by salicylate administration in the present study. However, heart rates in horses with lameness induced by an adjustable heart bar shoe were shown to be decreased with intravenous phenylbutazone (Foreman et al., 2008). This is another area in need of further scrutiny.

Canine and equine trials evaluating nonsteroidal antiinflammatory drugs with objective analysis of lameness by using force plate analysis and gait analysis have been published (Vasseur et al., 1995; Toutain et al., 2001; Erkert et al., 2005; Ishihara et al., 2005; Schoonover et al., 2005; Moreau et al., 2007). These studies have found nonsteroidal antiinflammatory drugs to improve force plate readings in treated subjects. These technologies have also been applied in field conditions in cattle (Kujala et al., 2008), but no research has been published using a bovine synovitis-arthritis model to assess lameness objectively. Pressure mat technol- 
ogy can be used to define pressure distribution, stride length, stance duration, and contact area during the stance phase of locomotion after corrective trimming, and during active locomotion. The results of this study demonstrate no overall difference between salicylate and placebo-treated animals in terms of pressure mat readings of contact surface area, stance phase duration, or contact pressure.

\section{CONCLUSIONS}

In conclusion, amphotericin B at 15 and $20 \mathrm{mg}$ by intraarticular injection provides an effective model for lameness. Intravenous sodium salicylate at $50 \mathrm{mg} / \mathrm{kg}$ once daily is ineffective in providing analgesia in induced lameness because of the very short half-life in cattle. Further studies at higher concentrations and increased frequency are needed to determine the efficacy of sodium salicylate in alleviating the pain associated with lameness.

\section{ACKNOWLEDGMENTS}

J. F. Coetzee is supported by the USDA-Cooperative State Research, Education, and Extension ServiceNational Research Initiative, Animal Well Being Section (grant no. 2008-35204-19238). J. L. Kotschwar is supported by the Beef Cattle Institute at Kansas State University. The authors acknowledge the invaluable contributions of the following Kansas State University staff and students who assisted with the care of the study animals, sample collection, and processing: Scott Ruthstrom, Tom Wegman, Sarah Barron, Nathan Kotschwar, Brad Robert, Tiffany Lee, Charlie Cull, Audrey Collinet, Sami Miles, Katie Hope, Craig Pauly, Brian Lubbers, Brandon Reinbold, Debra Wilcox, and Monica Lachowsky. Kara Smith from the Kansas State University Veterinary Clinical Science laboratory also provided excellent technical expertise and assistance.

\section{REFERENCES}

American Veterinary Medical Association. 2001. Welfare on the farm: Treating pain and distress in food animals. AVMA Animal Welfare Forum. http://www.avma.org/onlnews/javma/dec01/s121501d. asp Accessed Nov. 20, 2008

Anderson, D. E., and W. W. Muir. 2005. Pain management in cattle. Vet. Clin. North Am. Food Anim. Pract. 21:623-635.

Anil, S. S., L. Anil, and J. Deen. 2002. Challenges of pain assessment in domestic animals. JAMA 220:313-319.

Berry, S. L. 2001. Milking the golden cow-Her comfort. JAMA 219:1382-1386.

Bicalho, R. C., L. D. Warnick, and C. L. Guard. 2008. Strategies to analyze milk losses caused by diseases with potential incidence throughout the lactation: A lameness example. J. Dairy Sci. 91:2653-2661

Bowman, K. F., R. C. Purohit, V. K. Ganjam, R. D. Pechman Jr., and J. T. Vaughan. 1983. Thermographic evaluation of corticosteroid efficacy in amphotericin B-induced arthritis in ponies. Am. J. Vet. Res. 44:51-56.

Coetzee, J. F., R. Gehring, A. C. Bettenhausen, B. V. Lubbers, S. E. Toerber, D. U. Thomson, B. KuKanich, and M. D. Apley. 2007. Attenuation of acute plasma cortisol response in calves following intravenous sodium salicylate administration prior to castration. J. Vet. Pharmacol. Ther. 30:305-313.

Cook, N. B. 2003. Prevalence of lameness among dairy cattle in Wisconsin as a function of housing type and stall surface. J. Am. Vet. Med. Assoc. 223:1324-1328.

Crawford, W. H., J. C. Houge, D. T. Neirby, A. Di Mino, and A. A Di Mino. 1991. Pulsed radio frequency therapy of experimentally induced arthritis in ponies. Can. J. Vet. Res. 55:76-85.

Erkert, R. S., C. G. MacAllister, M. E. Payton, and C. R. Clarke. 2005. Use of force plate analysis to compare the analgesic effects of intravenous administration of phenbutaxone and flunixin meglumine in horses with navicular syndrome. Am. J. Vet. Res. 66:284-288.

Fahmy, A. S., A. A. Hegazy, M. A. A. El-Hamied, A. A. Shamaa, and E. Schimke. 1994. Clinical, biochemical and histopathological studies on arthritis in equine. Vet. Med. J. Giza 42:305-320.

Flower, F. C., M. Sedlbauer, E. Carter, M. A. G. von Keyserlingk, D J. Sanderson, and D. M. Weary. 2008. Analgesics improve the gait of lame dairy cattle. J. Dairy Sci. 91:3010-3014.

Foreman, J. H., A. Barange, L. M. Lawrence, and L. L. Hungerford. 2008. Effects of single-dose intravenous phenylbutazone on experimentally induced, reversible lameness in the horse. J. Vet. Pharmacol. Ther. 31:39-44.

Francoz, D., A. Desrochers, N. Simard, Y. Saint Pierre, G. Fecteau, J. S. Latouche, and M. Fortin. 2008. Relative expression of matrix metalloproteinase-2 and -9 in synovial fluid from healthy calves and calves with experimentally induced septic arthritis. Am. J. Vet. Res. 69:1022-1028.

Hegazy, A. A., L. S. Fahmy, A. S. Fahmy, M. A. A. El-Hamied, A. A. Shamaa, and E. Schimke. 1994. Evaluation of the effects of intraarticular injection of dimethylsulfoxide on chemically induced arthritis in equines. Vet. Med. J. Giza 42:221-243.

Heleski, C. R., A. G. Mertig, and A. J. Zanella. 2004. Assessing attitudes toward farm animal welfare: A national survey of animal science faculty members. J. Anim. Sci. 82:2806-2814.

Hernandez, J. A., E. J. Garbarino, J. K. Shearer, C. A. Risco, and W. W. Thatcher. 2005. Comparison of the calving-to-conception interval in dairy cows with different degrees of lameness during the prebreeding postpartum period. J. Am. Vet. Med. Assoc. 227:1284-1291

Hernandez, J. A., J. K. Shearer, and D. W. Webb. 2002. Effect of lameness on milk yield in dairy cows. J. Am. Vet. Med. Assoc. 220:640-644.

Hoferl, M., S. Krist, and G. Buchbauer. 2006. Chirality influences the effects of linalool on physiological parameters of stress. Planta Med. 72:1188-1192.

Ishihara, A., A. L. Bertone, and P. J. Rajala-Shultz. 2005. Association between subjective lameness grade and kinetic gait parameters in horses with experimentally induced forelimb lameness. Am. J. Vet. Res. 66:1805-1815.

Kujala, M., M. Pastell, and T. Soveri. 2008. Use of force sensors to detect and analyse lameness in dairy cows. Vet. Rec. 162:365368.

Leon-Reyes, M. R., G. Castaneda-Hernandez, and M. I. Ortiz. 2008 Pharmacokinetic and pharmacodynamics of diclofenac in the presence and absence of glibenclamide in the rat. J. Pharm. Pharm. Sci. 11:68-76.

Marttinen, P. H., S. M. Raulo, M. M. Suominen, and R.-M. Tulamo. 2006. Changes in MMP-2 and -9 activity and MMP- 8 reactivity after amphotericin B induced synovitis and treatment with bufexamac. J. Vet. Med. 53:311-318.

Moreau, M., B. Lussier, M. Doucet, G. Vincent, J. Martel-Pelletier, and J. P. Pelletier. 2007. Efficacy of licofelone in dogs with clinical osteoarthritis. Vet. Rec. 160:584-588.

Roeber, D. L., P. D. Miles, C. D. Smith, K. E. Belk, T. G. Field, J. D. Tatum, J. A. Scanga, and G. C. Smith. 2001. National market cow 
and bull beef quality audit-1999: A survey of producer-related defects in market cows and bulls. J. Anim. Sci. 79:658-665.

Sall, J., L. Creighton, and A. Lehman. 2004. JMP Start Statistics. 3rd ed. Thomson Brooks/Cole, Belmont, CA.

Schellenberg, R., S. Sauer, and A. Brattstrom. 2004. The herbal tranquillizer Ze 185 vs. oxazepam - A clinical and neurophysiological pilot study. Z. Phytother. 25:289-295.

Schoonover, M. J., H. W. Jann, and M. A. Blaik. 2005. Quantitative comparison of three commonly used treatments for navicular syndrome in horses. Am. J. Vet. Res. 66:1247-1251.

Smith, G. W., J. L. Davis, L. A. Tell, A. I. Webb, and J. E. Riviere. 2008. Extralabel use of nonsteroidal anti-inflammatory drugs in cattle. J. Am. Vet. Med. Assoc. 232:697-701.

Sprecher, D., D. Hostetler, and J. Kaneene. 1997. A lameness scoring system that uses posture and gait to predict dairy cattle reproductive performance. Theriogenology 47:1179-1187.

Stilwell, G., M. S. Lima, and D. M. Broom. 2008. Effects of nonsteroidal anti-inflammatory drugs on long-term pain in calves castrated by use of an external clamping technique following epidural anesthesia. Am. J. Vet. Res. 69:744-750.

Ting, S. T. L., B. Earley, J. M. L. Hughes, and M. A. Crowe. 2003. Effect of ketoprofen, lidocaine local anesthesia, and combined xylazine and lidocaine caudal epidural anesthesia during castration of beef cattle on stress responses, immunity, growth, and behavior. J. Anim. Sci. 81:1281-1293.

Toutain, P. L., C. C. Cester, T. Haak, and V. Laroute. 2001. A pharmacokinetic/pharmacodynamic approach vs. a dose titration for the determination of a dosage regimen: the case of nimesulide, a Cox-2 selective nonsteroidal anti-inflammatory drug in the dog. J. Vet. Phar. Ther. 24:43-55.

Tuschen-Caffier, B., and C. Vogele. 1999. Psychological and physiological reactivity to stress: An experimental study on bulimic patients, restrained eaters and controls. Psychother. Psychosom. 68:333-340.

USP Veterinary Pharmaceutical Information Monographs. 2004. Antiinflammatories. J. Vet. Pharmacol. Ther. 27(Suppl. 1):4-14

Vasseur, P. B., A. L. Johnson, S. C. Budsberg, J. D. Lincoln, J. P. Toombs, J. G. Whitehair, and E. L. Lentz. 1995. Randomized, controlled trial of the efficacy of carprofen, a nonsteroidal antiinflammatory drug, in the treatment of osteoarthritis in dogs. J. Am. Vet. Med. Assoc. 206:807-811.

von Borell, E., J. Langbein, G. Després, S. Hansen, C. Leterrier, J. Marchant-Forde, R. Marchant-Forde, M. Minero, E. Mohr, A. Prunier, D. Valance, and I. Veissier. 2007. Heart rate variability as a measure of autonomic regulation of cardiac activity for assessing stress and welfare in farm animals - A review. Physiol. Behav. 92:293-316.

Wells, S. J., A. M. Trent, W. E. Marsh, and R. A. Robinson. 1993. Prevalence and severity of lameness in lactating dairy cows in a sample of Minnesota and Wisconsin herds. J. Am. Vet. Med. Assoc. 202:78-82. 